\title{
Surface fair-weather potential gradient measurements from a small tropical island station Suva, Fiji
}

\author{
Vickal V. Kumar*, V. Ramachandran, V. Buadromo, and J. Prakash \\ School of Engineering and Physics, Faculty of Science and Technology, The University of the South Pacific, Suva, Fiji
}

(Received December 18, 2007; Revised October 21, 2008; Accepted October 30, 2008; Online published July 27, 2009)

\begin{abstract}
Systematic analysis of the surface fair-weather potential gradient (PG) measured for 13 months (July 2005July 2006) at $10 \mathrm{~s}$ resolution over a small tropical island station Suva $\left(18.08^{\circ} \mathrm{S}, 178.45^{\circ} \mathrm{E}\right)$, Fiji is presented. Based on the solar radiation $\left(>800 \mathrm{~W} \mathrm{~m}^{-2}\right)$ and surface wind speed $\left(<4.5 \mathrm{~m} \mathrm{~s}^{-1}\right)$ conditions, 63 fair-weather days were selected. After sorting the data into a range of $0-1000 \mathrm{~V} \mathrm{~m}^{-1}$, the average PG was $\sim 139 \mathrm{~V} \mathrm{~m}^{-1}$. The measured fair-weather PG had a semi-diurnal structure, with a more pronounced peak at 0730 LT (1930 UT) and a reduced peak at $2200 \mathrm{LT}$ (1000 UT). The time of occurrence of the morning peak and the noontime minima agreed well with the Carnegie curve. However, the variation about the global mean in the measured PG was $150 \%$ whereas for the Carnegie curve it was only $35 \%$. The effects of the local meteorological parameters on the PG measurements were found to be small. On average, the PG during the dry season (May-October) was always greater than in the wet season (November-April). In contrast, analysis of regional $\left(0-60^{\circ} \mathrm{S}\right.$ and $\left.100^{\circ} \mathrm{E}-160^{\circ} \mathrm{W}\right)$ lightning activity on fair-weather days showed a peak at $\sim 2000$ LT and higher lightning activity during the wet season. These results indicate that the regional thunderstorm activity has no direct connection with the local fair-weather PG at the site.
\end{abstract}

Key words: Fair-weather potential gradient, oceanic region, DC global electrical circuit, lightning.

\section{Introduction}

It is important to continue investigating the electrical properties of the atmosphere due to their relevance to climate change (e.g. Williams et al., 2003) and their connection with space weather (e.g. Tinsley et al., 2007). In spite of the long history of research in this field (Wilson, 1920), the causal mechanism for the variations in the Earth's electrical environment is not completely understood (Panneerselvam et al., 2003; Reddell et al., 2004). Possible reasons for this are, most of the atmospheric electrical measurements were episodic and the results were seldom complemented with the in situ meteorological data (Israelsson and Tammet, 2001).

A popular model for the DC global electrical environment assumes two spherical equipotential layers, the Earth's surface (negative) and the highly conducting lower region of the ionosphere (positive), connected together by the weakly conducting lower and middle atmosphere. The positive equalizing layer is normally at a potential of $180 \mathrm{kV}-400 \mathrm{kV}$ higher than the ground layer, which sets up a downward directed potential gradient (PG) within the Earth's atmosphere (Volland, 1984). Despite charge neutralization, the potential difference is constantly maintained by the global thunderstorm activity, based on the assumption that negative charges are transferred to the earth from

\footnotetext{
*Now at La Trobe University, Melbourne.
}

Copyright (c) The Society of Geomagnetism and Earth, Planetary and Space Sciences (SGEPSS); The Seismological Society of Japan; The Volcanological Society of Japan; The Geodetic Society of Japan; The Japanese Society for Planetary Sciences; TERRAPUB. the lower region of the thunderclouds and positive charges are transferred to the upper equalizing layer from the thunderheads (Wilson, 1920). Therefore, the thunderclouds complete the DC global electrical circuit (GEC).

Thunderclouds are more common during the local midafternoons (1400 hrs-1800 hrs) and their occurrence rate is nearly 10 times higher over land than over sea (Williams and Heckman, 1993). Since the Northern Hemisphere (NH) has a comparatively large landmass, its thunderstorm activity outweighs that in the Southern Hemisphere (SH), hence the NH thunderstorms may have a dominant effect on GEC.

In regions far away from thunderstorm areas, a downward directed ionic current density of the order $\sim 3 \mathrm{pA} \mathrm{m}^{-2}$ flows between the positive equalizing layer and the ground. The current is infinitesimal due to a limited concentration of mobile ions in the lower and middle atmosphere. In general, the mobility of the ions in the atmosphere increases exponentially with the altitude. Thus, the specific resistance $\rho_{\mathrm{h}}$ decreases exponentially with the altitude and peaks close to the Earth's surface. However, the total columnar resistance ${ }^{1} r_{\mathrm{s}}$ (units $\Omega \mathrm{m}^{2}$ ) between the upper and the lower layers is constant with time, having different values over sea and land (Volland, 1984).

Using the aforementioned atmospheric electrical parameters, the vertical profile for the Earth's fair weather electric field $\mathbf{E}_{\mathrm{h}}$ is given as $\mathbf{E}_{\mathrm{h}}=\rho_{\mathrm{h}} V / r_{\mathrm{s}}$, where $V$ is the potential of the equalizing layer (e.g. Harrison and Aplin, 2002). Note that the downward directed current density $V / r_{\mathrm{s}}$ is ap-

\footnotetext{
${ }^{1} r_{\mathrm{s}}$ defined as the total resistance of a unit cross sectional area of space between the surface of the earth and the electrosphere.
} 
proximately constant with the altitude, thus the variability in $\mathbf{E}_{\mathrm{h}}$ is directly proportional to the variability in $\rho_{\mathrm{h}}$. Close to the surface, the PG values during fair-weather conditions normally range from $100 \mathrm{~V} \mathrm{~m}^{-1}-200 \mathrm{~V} \mathrm{~m}^{-1}$.

Surface fair-weather PG measurements have been frequently used to investigate the electrical properties of the atmosphere, be it global, regional or local (Latha, 2003). Long term measurements of PG over the oceans feature a clear global diurnal pattern with a peak around 1900 UT and this trend is known as the Carnegie Curve (Israel, 1973). The Carnegie curve is in good agreement with the diurnal variation in the global thunderstorm activity and this connection was first demonstrated by Whipple (1929).

Despite the global origin of fair-weather electric fields, their magnitude close to the Earth's surface may be strongly mediated by the local meteorological conditions. Several early studies reveal high divergence in the measured PG from the Carnegie curve, which are mainly attributed to the local influence of turbulence, weather, smoke, aerosols and other anthropogenic factors (Israel, 1973; Israelsson and Tammet, 2001; Latha, 2003; Harrison, 2004). Thus, the atmospheric electrical measurements must be made in clean air sites, in order to detect changes in the output of the GEC.

One such clean air site may be the University of the South Pacific (USP) $\left(18.08^{\circ} \mathrm{S}, 178.45^{\circ} \mathrm{E}\right)$, which is located on the small tropical island of Fiji in the middle of the South Pacific Ocean. A 50-year (1910-1960) investigation of the atmospheric conductivity variations over the remote South Pacific oceans revealed that it had remained fairly constant while other regions had shown notable changes (Cobb and Wells, 1970). However, the ground-based fair-weather PG data from this region has been extremely rare; the last measurement was carried out in 1924 in Samoa (Thomson, 1924). The analysis of observations made at many locations around the world is required to better understand the GEC.

In this paper, we aim to compare the diurnal variation of fair weather PG measurements taken at USP for a 13month interval (July 2005-July 2006) with the Carnegie curve and determine whether this is a globally representative site. The diurnal and seasonal analyses of the regional lightning activity were also conducted to investigate if these contribute towards any variation in the $\mathrm{PG}$ recorded at the station. The finer variations in PG on selected fair-weather days and the concurrent local meteorological parameters are also presented.

\section{Instrumentation and Data Selection}

Continuous measurement of the fair-weather PG and the meteorological parameters were made at the Communication Research Facility at USP, Suva. The experimental site was $\sim 1 \mathrm{~km}$ from the coastline and $\sim 2 \mathrm{~m}$ above the sea level. There was no source of direct pollution in the vicinity and the nearest industrial area was located $\sim 4 \mathrm{~km}$ inland.

An electrostatic field meter JCI 131 was used to record the surface PG. The JCI 131 operates on the concept of field mills and produces a continuous analog output signal proportional to the incident electric field at the sensing aperture. The noise level of the instrument was less than $1 \mathrm{~V} \mathrm{~m}^{-1}$. The JCI 131 was mounted with sensing aperture at $2 \mathrm{~m}$ above the ground on a vertical galvanised pole and was at least $25 \mathrm{~m}$ away from nearby trees, buildings and power lines. A thick insulator separated the field mill from its support.

The sensitivity of the JCI 131 is a function of the installation height and changes automatically when the ambient field varies appreciably. At the sensing height of $2 \mathrm{~m}$, the sensitivity ranges were $0.1,1,10$ and $100 \mathrm{kV} \mathrm{m}^{-1}$. The operating sensitivities were indicated by a 2-bit logic system. The analog output voltage and the sensitivity levels were recorded at 10 -sec resolution on a $\mathrm{PC}$ via the commercially available LabVIEW data acquisition system. A positive PG represents downward directed electric field.

The calibration of JC I131 was done at the commencement and at the conclusion of the study interval, at the manufacturer's facility. No significant discrepancies in the calibration constant were noted at each sensitivity range.

The meteorological parameters, namely horizontal wind speed, relative humidity, air temperature, and solar radiation were recorded using conventional equipment at 1-minute resolution via a data logger. The clock of the data logger and the PC were regularly synchronized. The time deviation was less than $8 \mathrm{~s}$ per week. The local time (LT) for the Fiji Islands is equivalent to UT $+1200 \mathrm{hrs}$. The time format used in this paper is quoted in HHMM format.

The classification of a day as a 'fair-weather' day has been varying among researchers. Ideally a fair-weather day should be cloudless. However, according to Cobb and Wells (1970), such restrictions are too severe for a maritime environment and they considered cloudy days with no visible precipitation also as fair-weather days.

The UK meteorological system sorts the fair-weather days into different categories based on hourly mean PG amounts. These are ' $0 \mathrm{a}$ ' to ' $2 \mathrm{c}$ ', where the numbers indicate the number of hours when the mean PG is negative ('0' always positive) and the letters correspond to the magnitude of PG ('a' always below $1000 \mathrm{~V} \mathrm{~m}^{-1}$ ) (e.g. Harrison, 2003). At Vostok station, fair-weather data were selected on the basis of electric field values alone, and spikes (change of $50 \mathrm{~V} \mathrm{~m}^{-1}$ within 5 mins) were rejected (Burns et al., 2005).

On most days, the overhead atmosphere at Suva was covered in full or part with cirrus/cirrostratus clouds and a mean solar radiation of $850 \mathrm{~W} \mathrm{~m}^{-2}$ was recorded near the solar zenith. For this site, a day was classified as a fairweather day if it showed a smooth parabolic variation in solar radiation with a peak intensity of at least $800 \mathrm{~W} \mathrm{~m}^{-2}$, no precipitation and the horizontal wind speed was below $4.5 \mathrm{~m} \mathrm{~s}^{-1}$ (Latha, 2003). Based on this classification, 63 fair-weather days were found during the study interval.

A close examination of the daily fair-weather data revealed that at times the potential at the sensing aperture showed large spikes with measurements shifting to $10 \mathrm{kV}$. This was attributed to foreign particles (pieces of grass, leaves etc.) coming in contact with the sensing aperture of the field mill. As a compromise, minute averages of PG which were within the range of $0-1000 \mathrm{~V} \mathrm{~m}^{-1}$ (equivalent to ' 0 a' criteria), were individually selected from the 63 fairweather days and these were used for the analysis presented in this paper. 


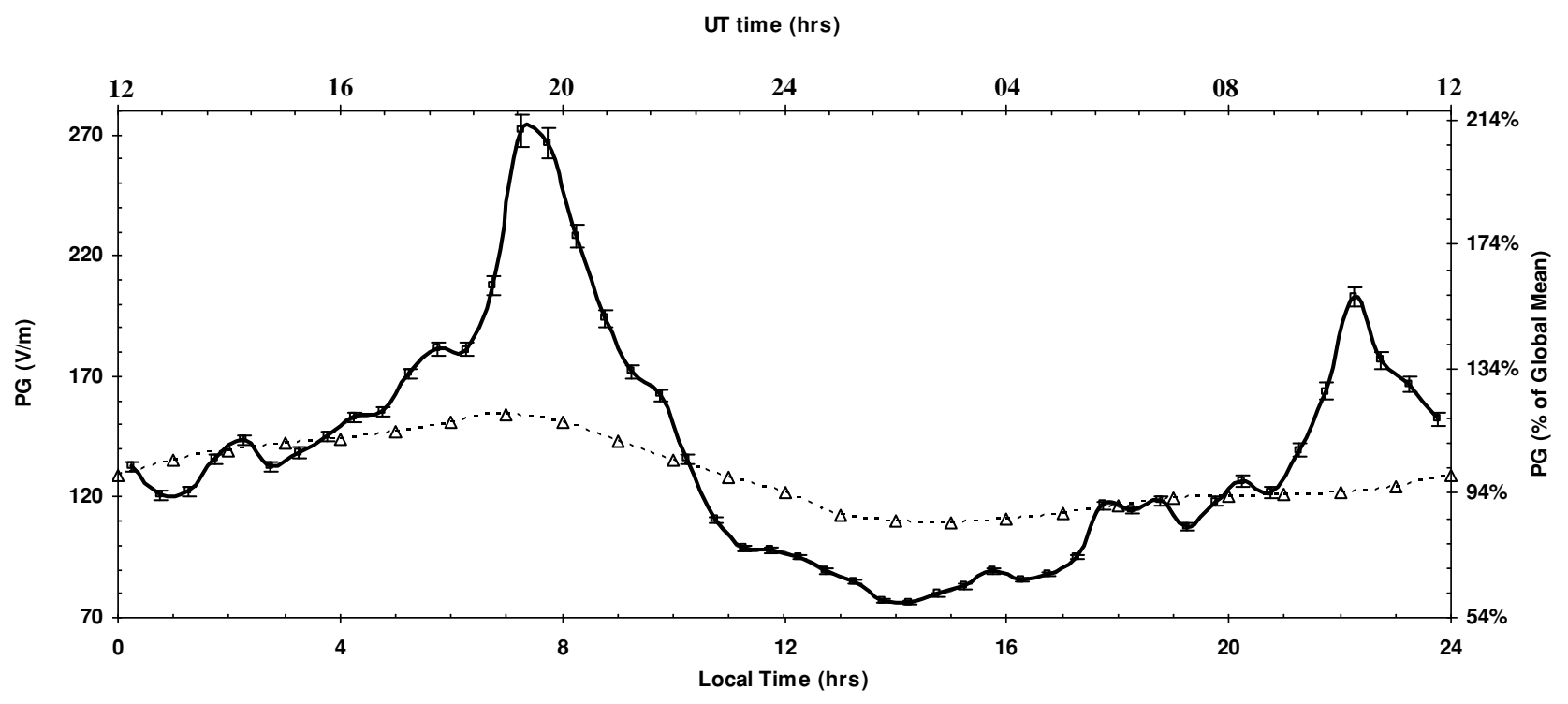

Fig. 1. The mean fair-weather diurnal variation in PG at Suva for July 2005-July 2006 (solid black), and the Carnegie curve (dotted black). The error bars represent standard errors, as explained in the text. The secondary $y$-axis represents the ratio (in percentage) in the measured PG values and Carnegie curve values with respect to the global mean of $129.2 \mathrm{~V} \mathrm{~m}^{-1}$. Data for Carnegie curve is given by Harrison (2004).

\section{Results and Discussion}

In Fig. 1, the mean diurnal variation of PG for 63 fairweather days is given by a solid curve and the Carnegie curve is represented using a dotted curve. The measured diurnal variation in PG was obtained by averaging the data using a bin size of 30 minutes. Lower integration times $(<15$ mins) produced rapid small scale fluctuations in the trend but the main features were reproducible. The error bars in this and all the subsequent figures are standard errors, $\sigma / \sqrt{n}$ where $\sigma$ is the standard deviation and $n$ is the number of samples in each 30 minute bin. The secondary $y$-axis represents the ratio (in percentage) of the PG values to the Carnegie mean of $129.2 \mathrm{~V} \mathrm{~m}^{-1}$.

\subsection{Comparison with global trends}

The landmass of the Pacific Island countries is relatively small and is surrounded by an oceanic environment, which may lead to the formation of complex atmospheric conductivities close to the surface. The Carnegie curve was also obtained from measurements done over a sea vessel, thus closeness in the measured PG with the Carnegie curve could be expected.

In Fig. 1, the dominant morning maxima and noontime minima in the measured PG coincides well with the maxima (1900 UT) and minima (0230 UT) in the Carnegie curve. However, the percentage variation in the measured PG and the Carnegie curve were $150 \%$ and $35 \%$ respectively. The maximum deviation between the two trends occurred at $\sim 0700 \mathrm{LT}$ and this was attributed to the peaking of GEC and the sunrise effect. Both these mechanisms occurred in the same local time sector for this station and thus may have caused unusually large enhancement in the measured PG during the morning.

The sunrise effect has been explained using the electrode effect, which is a build-up of positive charge in the air near the surface of the negatively charged Earth (the electrode) (Hoppel et al., 1986; Marshall et al., 1999). Radiative cooling through the night can produce very stable temperature profiles immediately before sunrise (Moore et al., 1962). During this period, the electrode layer would be generally below the sensing height of $2 \mathrm{~m}$. This may explain the short dip in the PG values as seen later in Fig. 4(a) but the presunrise dip is missing in Fig. 1. By sunrise, upward convective mixing lifts the dense electrode-layer above the sensing height, and thus enhances the PG measurements. Law (1963) has also shown a steep variation in the fair-weather space charge during sunrise changing from negative in the night to positive during the day.

A few hours after sunrise, the solar heating of the surface leads to convective instability which causes mixing that washes out the electrode-layer and allows the PG to return to its typical fair-weather values (Moore et al., 1962). Marshall et al. (1999) explained that if the measurement site is close to water bodies viz oceans or rivers then the sunrise effect could be dominant. Our measurement site was close to the sea, hence the observed dominance. Furthermore, Blanchard (1966) found that sea spraying generates positive charges which would enhance the PG measurements. Apart from the sunrise effect, at other times the contributions of local meteorological variations on the measured PG were small. This is further discussed in Section 3.3.

The semidiurnal patterns reported at other sites, also including Suva are summarized in Table 1. Clearly, at all the sites except for Pune, the observed peak around 1900 UT was the more intense of the two peaks (primary maxima). At Pune, the sunrise effect (0430 UT) was more pronounced and this was attributed to aerosols, because of the time of occurrence (0900 LT) and given its tropical semi-urban industrial surroundings (Latha, 2003). At another tropical station, Tirunelveli, it was reported from 2 months of data that the sunrise effect was short lived while the evening maxima (1900 UT) was prolonged (Panneerselvam et al., 2003). For all stations mentioned in Table 1 except for Suva and Vostok, the measured peak around 1900 UT was in the local afternoon or evening, which overlaps with the peak in the 
Table 1. Summary of the PG patterns reported from other stations.

\begin{tabular}{cccccccc}
\hline \multirow{2}{*}{ Location } & \multicolumn{2}{c}{ Peaks in LT } & \multicolumn{2}{c}{ Peaks in UT } & \multirow{2}{*}{ Region } & \multirow{2}{*}{ Semi-diurnal Months } & \multirow{2}{*}{ Reference } \\
& Morning & Evening & Pri. & Sec. & & Mar-May & Reddell et al. (2004) \\
\hline Amundsen-Scott & 0400 & $1800^{\dagger}$ & 1900 & 0500 & SH & Jun-Aug & Harrison (2004) \\
Central Paris & 0800 & $1800^{\dagger}$ & 1900 & 0900 & $\mathrm{NH}$ & Dec-Feb & Harrison and Aplin (2002) \\
Kew London & 0800 & $1900^{\dagger}$ & 1900 & 0800 & $\mathrm{NH}$ & All months & Latha (2003) \\
Pune, India & $0900^{\dagger}$ & 2100 & 0430 & 1530 & $\mathrm{NH}$ & May-Oct & This paper \\
Suva, Fiji & $0730^{\dagger}$ & 2200 & 1930 & 1000 & $\mathrm{SH}$ & Jun-Aug & Israelsson and Tammet (2001) \\
Sweden & 0700 & $1800^{\dagger}$ & 1900 & 0800 & $\mathrm{NH}$ & IR & Panneerselvam et al. (2003) \\
Tirunelveli, India & 0630 & $0030^{\dagger}$ & 1900 & 0100 & $\mathrm{NH}$ & May-Oct & Burns et al. (2005) \\
Vostok & $0400^{\dagger}$ & 1500 & 2100 & 0800 & $\mathrm{SH}$ & .
\end{tabular}

Keys; ${ }^{\dagger}$ more intense of the two peaks $=$ Primary $($ Pri) \& weaker $=$ secondary (Sec); IR-Insufficient recording time.

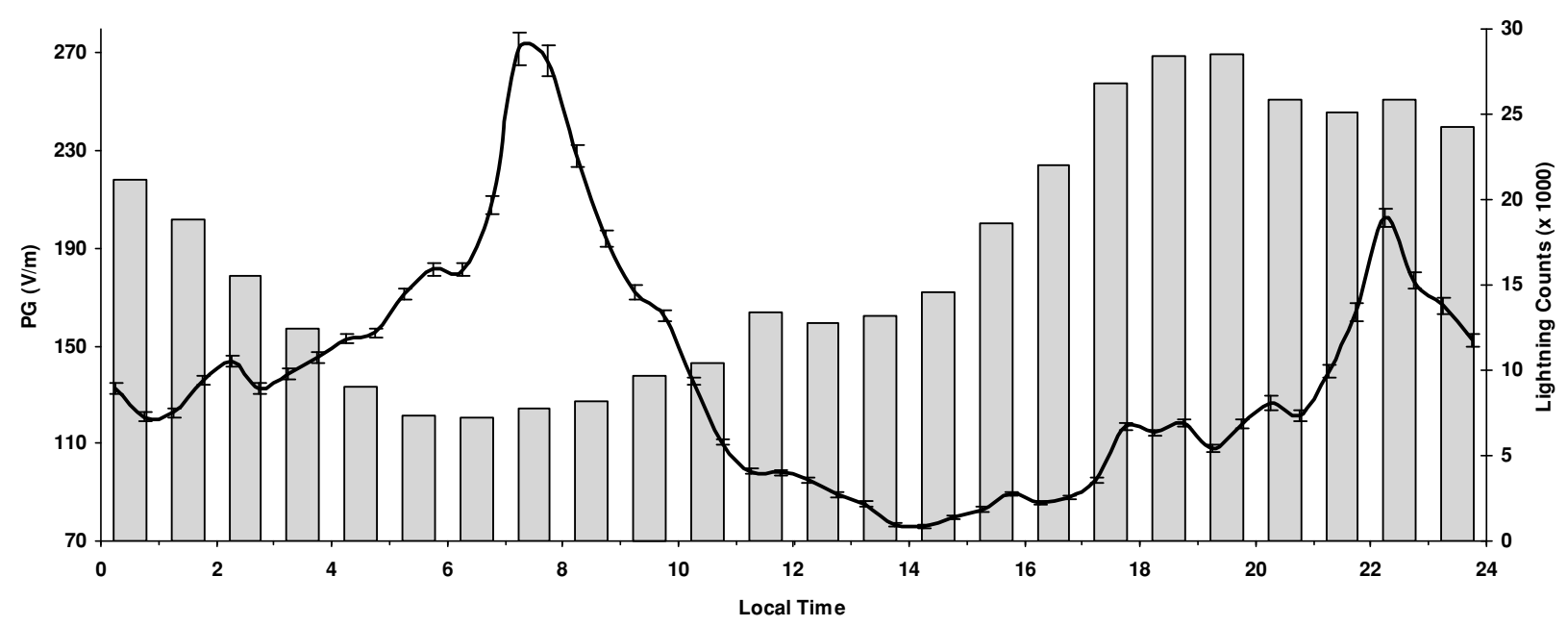

Fig. 2. Diurnal variation in the local PG (solid curve) and the total regional lightning counts (vertical bars) per hour on all fair-weather days between July 2005-July 2006.

respective regional thunderstorm activity. Using the data given in Table 1, on average the secondary maxima occurred around $0800 \mathrm{UT}$, and therefore the two peaks could be nearly twelve hours apart.

By comparison with the aforementioned tropical stations, it is suggested that the diurnal variations in the local PG are controlled by the GEC, local sunrise effect and possibly regional thunderstorm activity. At Suva, the time of occurrence of the sunrise effect coincided with the DC global electrical maximum; the two processes causing a more pronounced morning peak. Further, of the 3 tropical stations reported, Fiji has the smallest landmass with little industrial activity. Hence it is difficult to identify which process is having the most impact in determining the surface PG patterns in small tropical stations.

3.2 Investigating the effect of regional lightning activity on fair-weather electric field

In Fig. 1, a small peak in the PG was observed around 2200 LT (UT 1000), which cannot be associated with GEC or sunrise effect. Our hypothesis is this could be due to regional thunderstorm activity and will now be further explored.

The World Wide Lightning Location Network (WWLLN) detects cloud-to-ground lightning strikes around the globe and USP has been a member of this network since 2003. Using WWLLN archives, regional $\left(0-60^{\circ} \mathrm{S}\right.$ and $\left.100^{\circ} \mathrm{E}-160^{\circ} \mathrm{W}\right)$ lightning frequency was computed for the selected 63 fair-weather days. The total accumulation of lightning strikes per hour is presented in Fig. 2. Also included in Fig. 2 is the mean diurnal variation of the fair-weather PG. The regional thunderstorm activity was low around the dominant morning peak in PG. Peak thunderstorm activity was observed around 2000 LT, which was close to the time of the secondary maximum in PG (2200 LT).

The general climatology of the Fiji Islands has two distinct seasons; the wet season is from November to April and the dry season is from May to October. Marked differences were observed in the lightning activity between the two seasons, carried out using the Lightning Imaging Sensor satellite data and ground based WWLLN measurements (Ramachandran et al., 2005). Likewise, long-term rainfall studies at Suva also revealed distinct seasonal dependence (Kumar et al., 2006). In Fig. 3, the seasonal diurnal variations of the fair-weather PG together with the corresponding variation in the regional lightning activity are shown.

It is evident that the PG amounts in the dry season (black) were always greater than that in the wet season (red). Both seasons had a peak PG at $\sim 0700$ LT. The dry season PG further showed a bimodal variation with the secondary peak at $\sim 2200$ LT. It could be said that the dry season semidiurnal variation dominates the annual PG pattern. For the sun- 


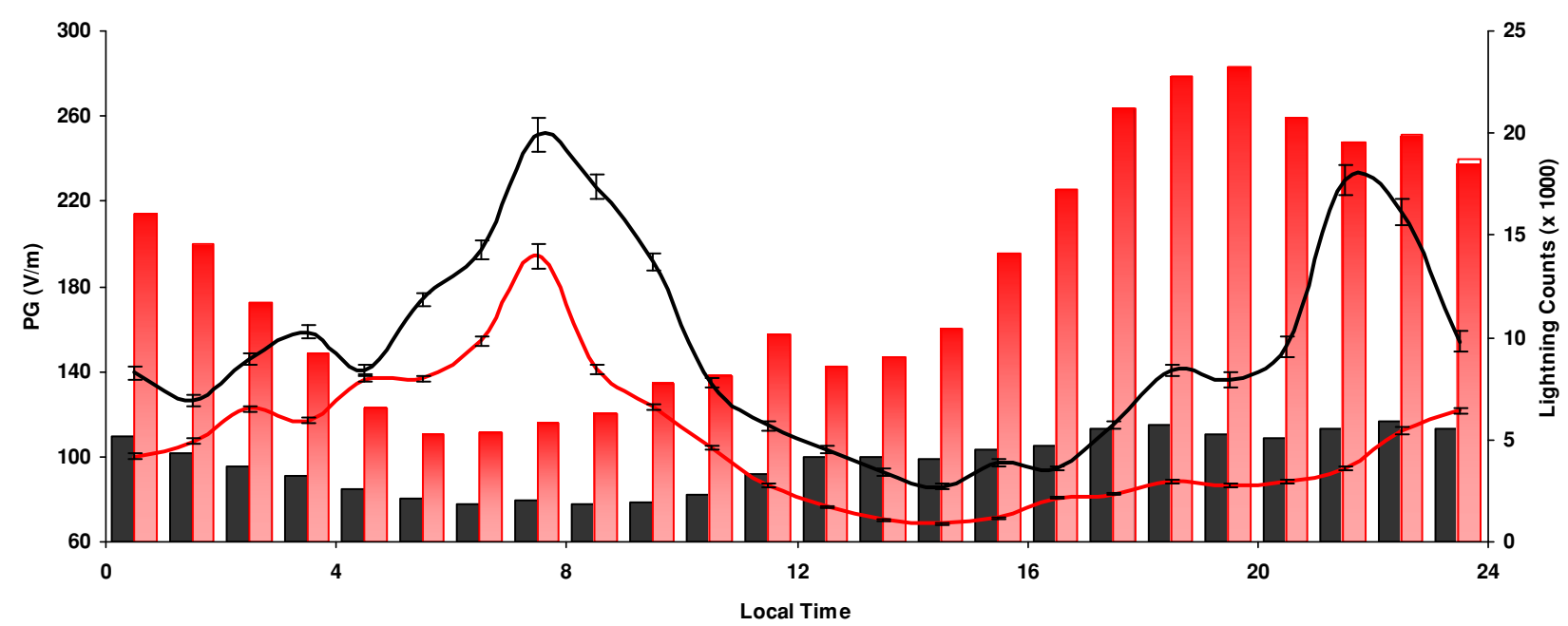

Fig. 3. Seasonal diurnal variation of fair-weather PG and lightning counts from July 2005-July 2006. The curves represent the measured PG values and the bars are for lightning counts. Black for the dry season and red for the wet season.

rise effect, the rate of change in PG was parallel for both seasons indicating that the mechanism causing this process is widespread throughout the year. In the wet season, the morning peak occurred $\sim 45$ minutes earlier than the dry season peak. This may be because the average sunrise time shifts early for the months November to April in the SH.

Comparing the lightning activity for the two seasons with the dominant peak in PG at $0700 \mathrm{LT}$, it is clear that the regional lightning effect does not contribute to the morning enhancement as the lightning activity was least during this time. For the wet season, during the evenings, the lightning activity was high but the PG values were low. For the dry season, the lightning activity was relatively high from 1200 noon to 0200 LT but a peak in the PG appears at 2200 LT. These observations suggest that the regional thunderstorm activity does not contribute to any diurnal variation in the measured $\mathrm{PG}$ at this site.

Compared to the $\mathrm{SH}$, the $\mathrm{NH}$ has greater thunderstorm occurrence due to the large landmass (Adlerman and Williams, 1996; Reddell et al., 2004), and thus adds more dominantly to the GEC. The dry months (May-October) of the Fiji islands chronologically correspond to the summer/spring season of temperate regions in the $\mathrm{NH}$, i.e. the NH thunderstorm season. Similarly, the wet months (November-April) overlap with the winter/autumn season in the NH. The PG measured at our site was high between May-October and likewise for most sites reported in Table 1, except for Kew. At Kew, the May-October months (summer season in Kew) had lower PG values and this was attributed to the reduction in smoke concentration (Harrison and Aplin, 2002). Our results suggest that the measured PG was not affected by the regional thunderstorm activity, instead it tends to follow the global thunderstorm activity, which is mainly governed by the thunderstorm activity in the NH.

\subsection{Local meteorological effects}

To investigate the effects of the local meteorological parameters, the PG values on 9 fair-weather days that had least data disruptions were analyzed against varying meteorological parameters and the results are shown in Fig. 4. This may point to the major meteorological contributors to any anomalous variation in the PG.

Figure 4(a) shows the mean diurnal variation in PG for the 9 days. Prior to averaging, the data were divided into bins of 30 mins. For Fig. 4(b), the PG values were sorted into 30-min bins of LT and $0.6^{\circ} \mathrm{C}$ bins of temperature. An average was determined separately for each bin, and is presented without smoothing. Figures 4(c) and 4(d) are in the same format as Fig. 4(b) and display for relative humidity (bin size of 2\%) and wind speeds (bin size of $0.2 \mathrm{~m} \mathrm{~s}^{-1}$ ), respectively.

According to Fig. 4(a), the PG showed a dip in amplitude around $0400 \mathrm{LT}$ followed by peaks at $\sim 0730 \mathrm{LT}$ and 2100 LT. On several fair weather days, within three hours of sunrise, the PG values reached magnitudes of $500 \mathrm{~V} \mathrm{~m}^{-1}$ $2000 \mathrm{~V} \mathrm{~m}^{-1}$. These large values were not consistent with the typical fair weather range and so PG values above $1000 \mathrm{~V} \mathrm{~m}^{-1}$ were excluded prior to the analysis.

The increasing phase of the sunrise effect in Fig. 4(a) and Fig. 1 was 2.5 hours long (0500 LT-0730 LT) and began to ascend $\sim 1 \mathrm{hr}$ before the actual ground sunrise (annual average sunrise time in Fiji is assumed to be 0600 LT). During this rising phase, the relative humidity was high (on average $90 \%)$, the temperature was low $\left(<24^{\circ}\right)$ and the wind speed was low $\left(<2 \mathrm{~m} \mathrm{~s}^{-1}\right)$. While the decreasing phase lasted for nearly 3.5 hours (0730 LT-1100 LT) and was coincident with the lowering in relative humidity, increases in the temperature and wind speed.

Apart from the connection at sunrise between the relative humidity, air temperature and PG, Figs. 4(b) and 4(c) indicate that the response in PG at other times was not well correlated with varying relative humidity and air temperature. For example, Fig. 4(c) indicates that between 0000 LT0500 LT, increased relative humidity caused enhancements of up to $130 \mathrm{~V} \mathrm{~m}^{-1}$ in the PG (purple-red) while no significant effect was noticed in the daytime.

The wind speed (Fig. 4(d)) variation displayed a more consistent association with the surface PG at all local times. Increasing wind speed reduces the surface PG values. Between $1000 \mathrm{LT}-1500 \mathrm{LT}$, the PG values reduced from 


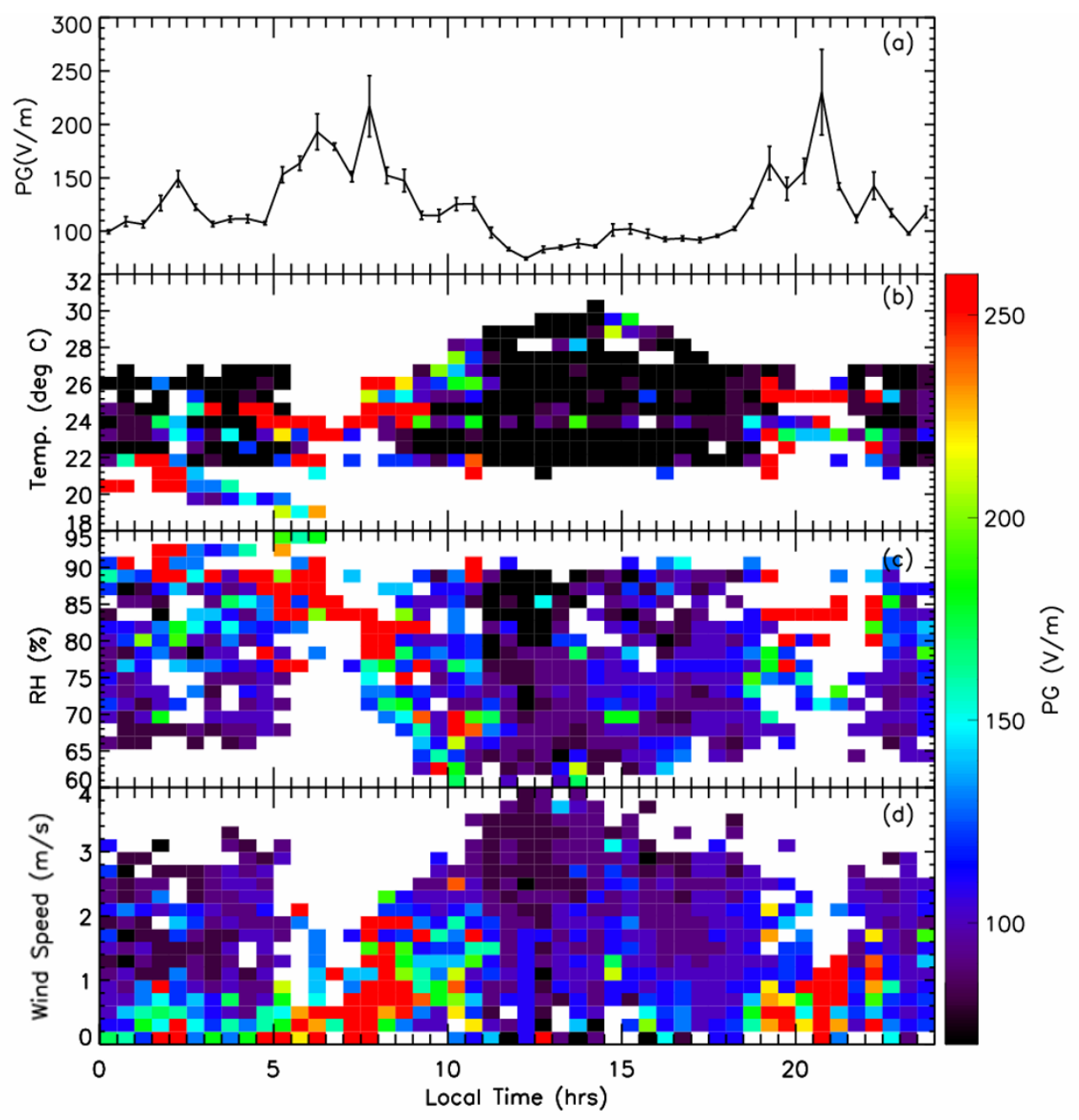

Fig. 4. Colour maps showing the response in fair-weather PG to varying meteorological conditions. These results were obtained using data from 9 fair-weather days. (a) Mean PG trend at 30 min integrations. (b) Color plot of PG, averaged into 30 min bins of local time and $0.6^{\circ} \mathrm{C}$ bins of air temperature. (c) The same as (b) and display relative humidity, RH, using bin size of $2 \%$. (d) The same as (b) and display wind speed using bin size of $0.2 \mathrm{~m} \mathrm{~s}^{-1}$. The color scale on the side represents averaged PG values and the tick marks on abscissa are 30 min intervals.

$\sim 100 \mathrm{~V} \mathrm{~m}^{-1}$ (bluish-purple) at $1 \mathrm{~m} \mathrm{~s}^{-1}$ to $\sim 75 \mathrm{~V} \mathrm{~m}^{-1}$ (purple) at $3.5 \mathrm{~m} \mathrm{~s}^{-1}$. Likewise, the $\mathrm{PG}$ values reduced by nearly $130 \mathrm{~V} \mathrm{~m}^{-1}$ (green to black) between $0000 \mathrm{LT}-$ 0300 LT. Suppression of fair-weather PG due to increased wind speed has also been observed at other stations (Marshall et al., 1999; Israelsson and Tammet, 2001).

Enhanced wind speed events may accelerate the washout of the electrode layer. This leads to a quicker drop in the PG to fair weather levels during the pre-midday sector. Also moderation by high wind speeds facilitates the generation of mobile charges close to the ground, obtained by rising fine sand and dust particles (Coffman, 1963). This would appreciably decrease the resistivity (i.e. increase conductivity) close to the surface. As explained in Introduction, to maintain an electrical equilibrium PG must be directly proportional to resistivity. This supports our observation that when the wind speed increased, the surface PG would reduce.

\section{Summary and Further Discussion}

The mean fair-weather PG showed a semidiurnal pattern, with a dominant peak at 0730 LT (1930 UT) and a sec- ondary peak at 2200 LT (1000 UT). The enhancement at 0730 LT was driven by two possible mechanisms; the local sunrise effect and the GEC which peaks at 1900 UT. The secondary peak at 2200 LT was stronger for the dry months (May-October), while it was missing for the wet months (November-April). Thus, the PG trend for the wet months had a better correlation with the Carnegie curve. Overall, the agreement between the Carnegie curve and the annual PG trend was largest in the post-mid-night sector (0000 LT0500 LT). We found no connection between the regional lightning activity and the PG variations.

At Suva, the daily average in fair-weather $P G$ was $139 \pm 7 \mathrm{~V} \mathrm{~m}^{-1}$ and this was relatively close to the Carnegie mean of $129 \mathrm{~V} \mathrm{~m}^{-1}$. In contrast, studies done over large continents have shown the mean PG is generally higher, for example, Scotland was $\sim 170 \mathrm{~V} \mathrm{~m}^{-1}$, London was $\sim 300 \mathrm{~V} \mathrm{~m}^{-1}$ (Harrison, 2003), Paris was $\sim 175 \mathrm{~V} \mathrm{~m}^{-1}$ (Harrison and Aplin, 2005), Athens was $\sim 200 \mathrm{~V} \mathrm{~m}^{-1}$ (Marcz and Harrison, 2005) and India was $\sim 100 \mathrm{~V} \mathrm{~m}^{-1}$ (Latha, 2003); these have been attributed to increases in aerosol concentration. The relatively low mean PG at Suva when compared to most stations may suggest that the at- 
mosphere over Suva is much cleaner. Also, the effects of meteorological parameters on the PG measurements were minimal (Fig. 4). The most significant perturbations were observed when wind-speeds exceeded $1 \mathrm{~m} \mathrm{~s}^{-1}$, and these weakly reduced the $\mathrm{PG}$ measurements.

Despite all this, the measured PG at Suva had much larger variation $(150 \%)$ when compared on the Carnegie curve (35\%). This could be partly due to the closeness of the measurement site to the sea $(2 \mathrm{~km})$. At the site, the wind direction continually changed but it was predominantly in the South-East direction, flowing from the sea to the experimental site. Blanchard (1966) showed that sea spraying generates positive charges which would enhance the PG measurements. Moreover, since the sunrise effect and the GEC mechanism occurred in the same local time sector (morning), their superposition would have further added to this anomaly. To separate the sunrise effect phase from the GEC cycle, the local solar time of a station should have a time difference of greater or less than $\sim 12$ hours with respect to UT time.

Our results and those summarized in Table 1 support the presence of a common (one) ionosphere-earth current loop across the Earth's atmosphere. The observations from this remote station in the $\mathrm{SH}$ provide results to researchers to better understand the GEC and its connection with fairweather electric fields. Moreover, our results will help to improve the understanding of the oceanic conductivity, especially for the South Pacific oceans, where atmospheric electrical data has been extremely rare.

Acknowledgments. This work was supported by the University of the South Pacific (Grant 62009). We thank all those people who helped to install and maintain the Field meter including, R. Lal, N. Singh, A. Deo and R. A. Lal. We thank WWLLN for providing lightning data over the region.

\section{References}

Adlerman, E. J. and E. R. Williams, Seasonal Variation of the Global Electric Circuit, J. Geophys. Res., 101(D23), 29679-29688, 1996.

Blanchard, D. C., Positive space charge from the sea, J. Atmos. Sci., 23, 507-515, 1966.

Burns, G. B., A. V. Frank-Kamenstsky, O. A. Troshichev, E. A. Bering, and B. D. Reddell, Interannual consistency of bi-monthly difference in diurnal variations of the ground-level, vertical electric field, J. Geophys. Res., 110, 1-14, 2005.

Cobb, W. E. and H. Wells, The electrical conductivity of oceanic air and its correlation to global atmospheric pollution, J. Atmos. Sci., 27, 814-819, 1970.

Coffman, M. L., Charging grains of dust, J. Geophys. Res., 68, 1565-1566, 1963.

Harrison, R. G., Twentieth century atmospheric electrical measurements at the observatories of Kew, Eskdalemuir and Lerwick, Weather, 58, 11$19,2003$.

Harrison, R. G., The global atmospheric electrical circuit and climate, Surv. Geophys., 25, 441-484, 2004.

Harrison, R. G. and K. L. Aplin, Mid-nineteenth century smoke concentration near London, Atmos. Enviro., 36(25), 4037-4043, 2002.
Harrison, R. G. and K. L. Aplin, Nineteenth century air pollution variation in Paris inferred from Eiffel Tower potential gradient measurements, Proc. 12th International Conference on Atmospheric Electricity, Versailles, Paris 9th-13th June 2003, 789-792, 2005.

Hoppel, W. A., R. V. Anderson, and J. C. Willett, Atmospheric electricity in the planetary boundary layer, in The Earth's Electrical Environment, 149-165, National Academic Press, Washington, D.C., 1986.

Israel, H., Atmospheric Electricity, vol. 2, Israel Program for Scientific Translations, Jerusalem, 1973.

Israelsson, S. and H. Tammet, Variation of fair-weather atmospheric electricity at Marsta Observatory, Sweden, 1993-1998, J. Atmos. Sol.-Terr. Phys., 63, 1693-1703, 2001.

Kumar, V., R. C. Deo, and V. Ramachandran, Total Rain Accumulation and Rain-Rate analysis for Small Tropical Pacific Islands: A Case Study of Suva, Fiji, Atmos. Sci. Lett., 7(3), 53-58, 2006.

Latha, R., Diurnal variation of surface electric field at a tropical station in different seasons: a study of plausible influences, Earth Planets Space, 55, 677-685, 2003.

Law, J., The ionisation of the atmosphere near the ground in fair weather, Quaterly J. Roy. Met. Soc., 89, 107-121, 1963.

Marcz, F. and R. G. Harrison, Further signatures of long-term changes in atmospheric electrical parameters observed in Europe, Ann. Geophys., 23, 1987-1995, 2005.

Marshall, C. T., W. D. Rust, M. Stolzenburg, P. W. Roeder, and R. P. Krebhiel, A study of enhanced fair-weather electric fields occurring soon after sunrise, J. Geophys. Res., 104(D20), 24455-24469, 1999.

Moore, C. B., B. Vonnegut, R. G. Semonin, J. W. Bullock, and W. Bradley, Fair-weather atmospheric electric potential gradient and space charge over central Illinois, summer 1960, J. Geophys. Res., 67, 1061-1071, 1962.

Panneerselvam, C., K. U. Nair, K. Jeeva, C. Selvaraj, S. Gurubaran, and R. Rajaram, A comparative study of atmospheric Maxwell current and electric field from a low latitude station, Tirunelveli, Earth Planets Space, 55, 679-703, 2003.

Ramachandran, V., S. Kumar, and A. Kishore, Remote sensing of cloud-toground lightning location using the TOGA of sferics, Atmos. Sci. Lett., 6, 128-132, 2005.

Reddell, B. D., J. R. Benbrook, E. A. Bering, E. N. Cleary, and A. A. Few, Seasonal variations of atmospheric electricity measured at AmundsenScott South Pole Station, J. Geophys. Res., 109, A09308, 1-17, 2004.

Thomson, A., Preliminary report on the atmospheric potential gradient recorded at Apia Observatory, Western Samoa, May 1992 to April 1924, Terr. Magn., 29, 97-100, 1924.

Tinsley, B. A., G. B. Burns, and L. Zhou, The role of the global electric circuit in solar and internal forcing of clouds and climate, J. Adv. Space Res., doi:10.1016/j.asr.2007.01.071, 2007 (in press).

Volland, H., Atmospheric Electrodynamics, 11th edn, Springer-Verlag Berlin Heidelberg, Germany, 4-28, 1984.

Whipple, F. J. W., On the association of the diurnal variation of electric potential on fine weather with the distribution of thunderstorms over the globe, in: Anderson R. V., 1967. Measurement of Worldwide Diurnal Atmospheric Electricity Variations, Mon. Weather Rev., 95(12), 899904, 1929.

Williams, E. R. and S. J. Heckman, The local diurnal variation of cloud electrification and the global diurnal variation of negative charge on earth, J. Geophys. Res., 98(D3), 5221-5234, 1993.

Williams, E. R., V. C. Mushtak, and D. J. Boccippio, Another look at the dependence of lightning flash rate on the temperature of boundary layer air in the present climate, Proc.12th International Conference on Atmospheric Electricity, 9-13 June, Versailles, France, 2003.

Wilson, C. T. R., Investigation of lightning discharges and on the electric field of thunderstorms, Philos. Trans. Roy. Soc. L., A221, 73-115, 1920.

V. V. Kumar (e-mail: kumar_vk@usp.ac.fj), V. Ramachandran, V. Buadromo, and J. Prakash 